\title{
A Broadband Left-Handed Metamaterial Microstrip Antenna with Double-Fractal Layers
}

\author{
Roman Kubacki, Salim Lamari, Mirosław Czyżewski, and Dariusz Laskowski
}

Faculty of Electronics, Military University of Technology, Warsaw, Poland

Correspondence should be addressed to Roman Kubacki; roman.kubacki@wat.edu.pl

Received 18 January 2017; Revised 11 March 2017; Accepted 6 April 2017; Published 7 May 2017

Academic Editor: Ariel Epstein

Copyright (C) 2017 Roman Kubacki et al. This is an open access article distributed under the Creative Commons Attribution License, which permits unrestricted use, distribution, and reproduction in any medium, provided the original work is properly cited.

\begin{abstract}
This paper proposes a microstrip patch antenna based on the left-handed metamaterial concept, using planar periodic geometry, which results in improved characteristics. This periodic geometry is derived from fractal shapes, which have been widely used in antenna engineering. The metamaterial property was obtained as a result of the double-fractal structure on both the upper and the bottom sides of the antenna. The final structure has been optimized to enhance bandwidth, gain, and radiation characteristics of the microstrip antenna. This combination significantly improved antenna performance; our design could support an ultrawide bandwidth ranging from 4.1 to $19.4 \mathrm{GHz}$, demonstrating higher gain with an average value of $6 \mathrm{dBi}$ over the frequency range and a peak of $10.9 \mathrm{dBi}$ and a radiation capability directed in the horizontal plane of the antenna.
\end{abstract}

\section{Introduction}

In commercial wireless communication systems, the antenna remains a key element of the communication chain. The efficiency of a radio broadcasting system is directly related to the characteristics of its antennas. In addition, future communication systems using cognitive radio or flexible radio will need smaller wideband antennas. In this paper, we focus on one of the common antenna designs-the microstrip patch antenna. This design has many advantages; it can be easily fabricated using a lithographic technique, it has a low profile, it has a low production cost, and its structure is fairly simple. However, these advantages are offset by the narrow bandwidth of the antenna. To date, several approaches have been proposed to address this deficiency. In most cases, the proposed solution was to increase the thickness and decrease the dielectric constant of the substrate at the same time. However, these attempts did not produce significant bandwidth enhancements in redesigned antennas.

Some specialised techniques were developed for bandwidth enhancement. One of such techniques involves the inclusion of additional resonators to the main patch. This can be done by inserting parasitic patch elements in a coplanar manner near the fed patch [1], or by stacking two or more patches [2]. Another technique is to ensure good impedance matching between the feed and the radiator and thus reduce reflection loss [3, 4]. This technique resulted in bandwidth enhancement of at most $30 \%$, but the aforementioned solutions require more space and thus invariably increase the size of the antenna. It is possible to obtain wideband characteristics while keeping the low profile of the patch antenna. To do so, one needs to cut " $U$ " shaped slots in the patch, or two parallel slits in one of the radiating edges, creating a shaped patch [5]. We note that these methods have the advantage of enhancing the bandwidth without augmenting the size of the microstrip antenna, but the most noticeable wideband capability, about $47 \%$, was obtained mainly using a design with foam and air substrates, which are not appropriate for arrays and would be challenging to integrate in microwave systems.

Taking into account the above-mentioned drawback of the antennas, the important task in microstrip antenna design is to create an antenna capable of supporting wideband or even ultrawideband (UWB) frequency range. With the development of new materials called left-handed materials (LHM), or left-handed metamaterials, it is possible to achieve a significantly wider frequency range. As a result, many 
antennas with LHM structures with better performance than conventional microstrip patch antennas were proposed.

At present, there is no clear classification of metamaterialbased antennas due to the fact that the problem is still not mature. Nevertheless, according to [6], two categories can be distinguished. The first category is the concept of a transmission line composed of a periodic repetition of a unit cell comprising a series capacitance and a shunt inductance [7]. This category is a direct application of the leaky-wave metamaterial antennas, which consists of a cascaded series of unit cells lying on a matched microstrip line $[8,9]$. This type is preferred for beam scanning applications. In the second category are the resonant antennas, which, in opposition to the first category, are obtained by terminating the structure to the free space by a short or open circuit [9]. The metamaterialbased resonant types of antenna structures allow dual-band, multiband behaviours and can be miniaturized but do not increase the bandwidth of the antenna.

However, even these LHM antennas cannot achieve a sufficiently wide frequency range. Many attempts have been proposed to widen the bandwidth of microstrip antenna using left-handed metamaterial structures. Among these, we can find a broadband planar antenna composed of a dipole and left-handed unit cells [10]. This configuration achieved a bandwidth of $1.2 \mathrm{GHz}$. Another model realized with $2 \times 2$ mushroom structure combined with a notch on the surface, with the entire structure on a solid ground plane, was proposed in [11]. Reflective metasurfaces placed above an ordinary patch antenna can be used to enhance the gain and reduce the size of the structure, using [12] $4 \times 4$ unit cells of reflective metasurfaces consisting of double closed rings suspended above a microstrip patch antenna. However, even this configuration achieved only $13 \%$ of bandwidth. A LHM antenna using a meander line is proposed in [11] where a single unit cell is incorporated with an interdigitated capacitor for the series capacitance, while the shunt inductance is produced by the meandered ground plane extension connected to the antenna by a via through the substrate. Still, most of the left-handed metamaterial-based antennas presented above are not wideband and have low gain and are thus unable to cover more than one wireless communication standard or claim to integrate high data rate transmission systems.

Planar left-handed metamaterial structures were proposed a few years ago [13]. The discussed structures consist of $2 \mathrm{D}$ periodic arrays of unit cells. This concept was applied to LHM antennas, resulting in broadband and high gain designs. The periodic patterns which showed left-handed characteristics were applied to rectangular conventional microstrip patch antennas. These configurations allowed obtaining a frequency range several times wider than the same patch antenna without the metamaterial pattern.

A perspective approach was proposed in [14] where a left-handed metamaterial antenna can achieve a broad bandwidth. This structure is a microstrip line loaded with different patterns on the metal parts of the substrate. On the top patch, the periodic gaps are designed in the form of isolated microtriangles, while, on the bottom ground plane, periodically distributed cross-strip gaps are designed.

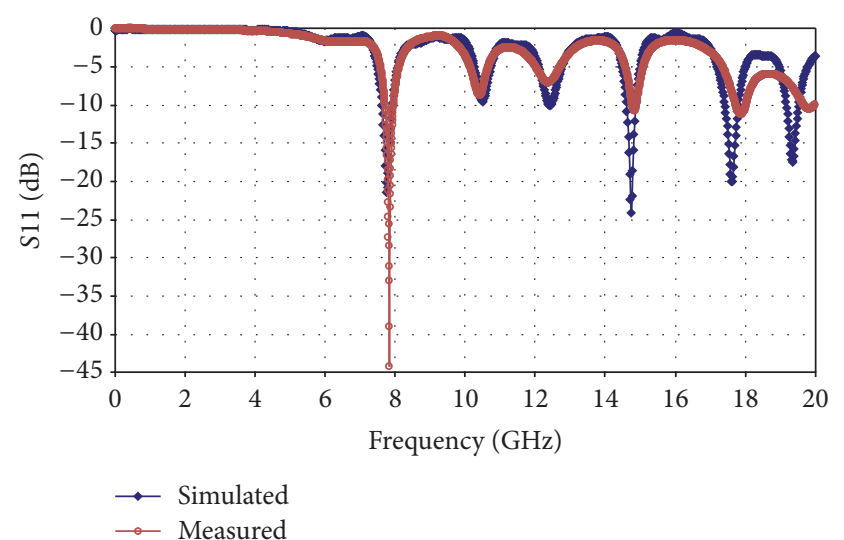

FIGURE 1: Results of the simulated and measured S11 values of the conventional microstrip antenna.

The structure achieves a significantly broader bandwidth of 3.2 GHz.

The main motivation of this work was to design an antenna with the widest possible bandwidth. This is why an ultrawideband microstrip antenna is presented. The concept of planar $2 \mathrm{D}$ left-handed metamaterial structure with periodic patterns is applied in order to enhance the bandwidth of a conventional microstrip patch antenna. The periodic patterns are formed by the repetition of a square unit cell along two axes. In fact, square unit cells, formed by the top and bottom layers of the dielectric substrate, consist of 2 different patterns on both layers. These patterns are inspired by fractal geometry, and their use is motivated by the benefits of fractals in antenna engineering [15-17].

Fractal based antennas are already presented in the literature, featuring patches with fractal structures. However, our proposed antenna geometry is novel due to its doublefractal layer design. Both layers of the antenna have fractal forms, but each patch includes different shapes. The upper side of the antenna follows the shape of crossbar fractals, with Minkowski fractals on the lower layer. The proposed selfsimilarity and ease of repetitiveness of the geometry make these designs attractive for creating a periodic structure.

The conventional microstrip patch antenna, which was used as a benchmark for comparison, produced a very limited bandwidth of $225 \mathrm{MHz}$. After introducing the planar metamaterial concept combined with double-fractal layers geometry, its bandwidth was multiplied by 68 , to more than $15 \mathrm{GHz}$.

\section{The Conventional Reference Antenna}

A rectangular microstrip patch antenna was designed to serve as a reference. The patch is $12 \times 16 \mathrm{~mm}^{2}$, and the feeding line is $2.46 \times 8 \mathrm{~mm}^{2}$. The simulated and measured $S 11$ values of the conventional reference antenna are presented in Figure 1.

\section{The Double-Fractal Layers Antenna Design}

The proposed metamaterial structure is in two-dimensional configuration. It is represented by a square unit cell of 


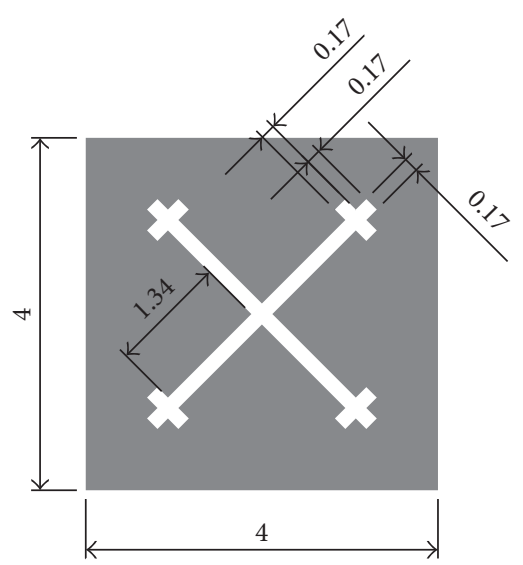

(a)

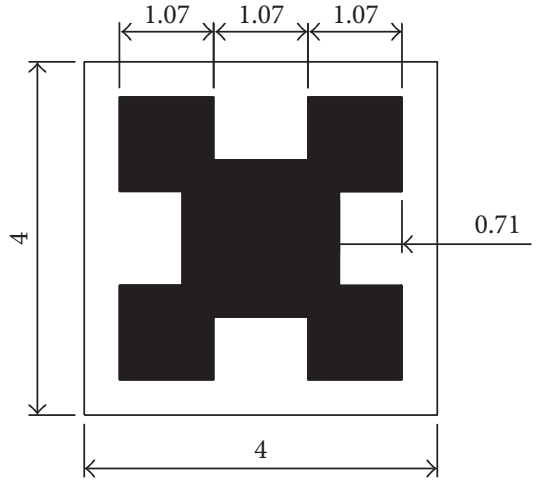

(b)

Figure 2: The fractal based elementary unit cells: (a) crossbar fractal for the top of the antenna, (b) Minkowski fractal for the bottom of the antenna (dimensions are in $\mathrm{mm}$ ).
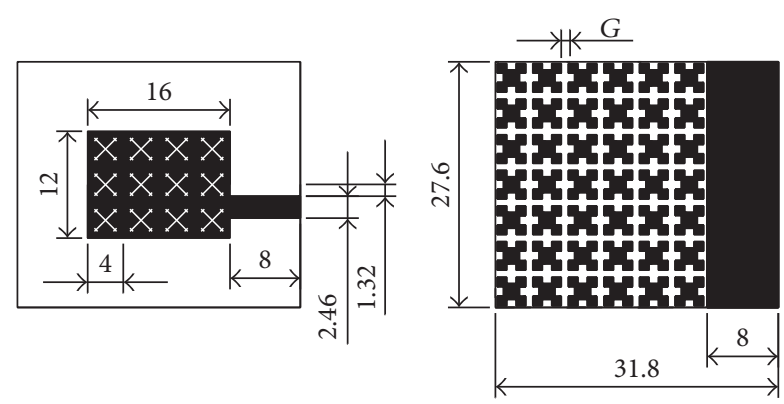

FIGURE 3: The proposed double-fractal antenna geometry.

$4 \times 4 \mathrm{~mm}^{2}$. The unit cell is composed of two planar metallic layers sandwiching a dielectric substrate. The two metallic layers were etched with two distinct fractal shapes. The crossbar fractal [18] diagonally lying on the square unit cell was etched out on the top. On the bottom, the Minkowski fractal $[19,20]$ in its first iteration was etched.

Constituent unit cells are depicted in Figure 2, while the view of double-fractal antenna geometry is presented in Figure 3. The entire structure of the proposed antenna measures $27.6 \times 31.8 \mathrm{~mm}^{2}$, with the same dimension for the feeding line (Figure 3 ). The antenna was designed with the Rogers RT 5880 low-loss substrate $(\tan \delta=0.0009$ at $10 \mathrm{GHz})$ with dielectric constant of 2.2 and thickness of $0.79 \mathrm{~mm}$. The upper patch consists of the $4 \times 3$ square unit cells with the diagonal crossbar fractal shape having the edge of $4 \mathrm{~mm}$ in a periodic arrangement (Figures 3 and 4). On the ground plane, composed of metallic patches separated by slot gaps, the Minkowski island fractals of $6 \times 7$ square unit cells are placed also in a periodic arrangement. This configuration improves the coupling between the patch and the ground plane by forming a capacitive-inductive (C-L) equivalent circuit which provokes the left-handed property. The view of the top and bottom sides of the antenna is presented in Figure 4.

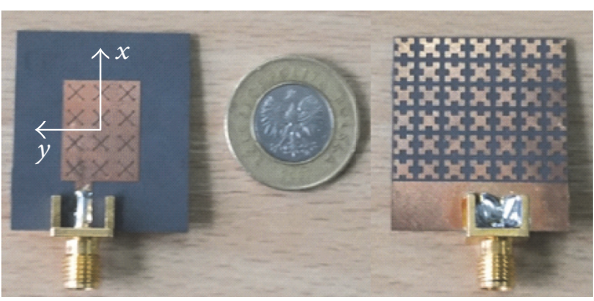

FIGURE 4: Picture of the fabricated antenna.

\section{Results and Discussion}

A parametric study was created to analyse the influence of the geometry on the performance of the antenna. In it, a variation in dimensions by the suitable increment, of one parameter at a time in the antenna geometry, is performed. The values of the dimensions giving the best performances of return loss (S11) will be obtained separately. These values are then combined together in order to obtain the optimal configuration of the antenna giving the best S11 performance and thus the largest bandwidth. We noticed that the width $G$ of the gap between the cells on the ground plane (Figure 3 ) has a significant effect on the $S 11$ value. Four dimensions of $G$ were investigated from $0.2 \mathrm{~mm}$ to $0.5 \mathrm{~mm}$, in increments of $0.1 \mathrm{~mm}$, and the resulting S11 values are presented in Figure 5.

From the plot, we noticed that when the width of the gap between the cells on the ground plane is the largest, which in our case is $0.5 \mathrm{~mm}$, so is the bandwidth. However, for higher values of $G$, the functions of $S 11$ get rapidly worse. For further investigation, $G=0.5 \mathrm{~mm}$ has been taken into account. The antenna with the optimal parameters resulting in the widest bandwidth was obtained and then fabricated, as depicted in Figure 4, to empirically measure the proposed microstrip antenna design. The measured S11 value of this antenna, in function of frequency, is presented in Figure 6. The figure shows good correlation between measured and simulated values and the very wide bandwidth of the proposed configuration. 


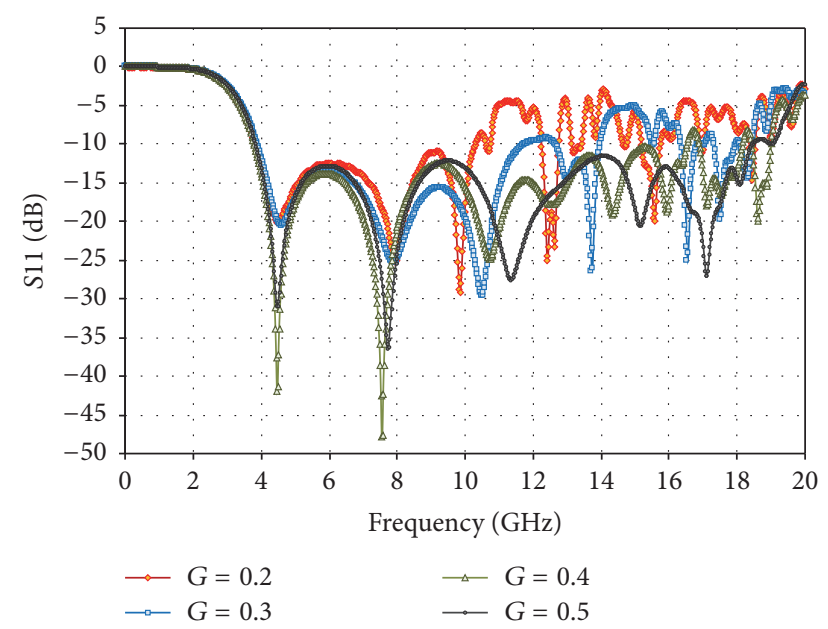

FIGURE 5: Results of simulation S11 with variation in the width of the gap between patches ( $G$ are in $\mathrm{mm}$ ).

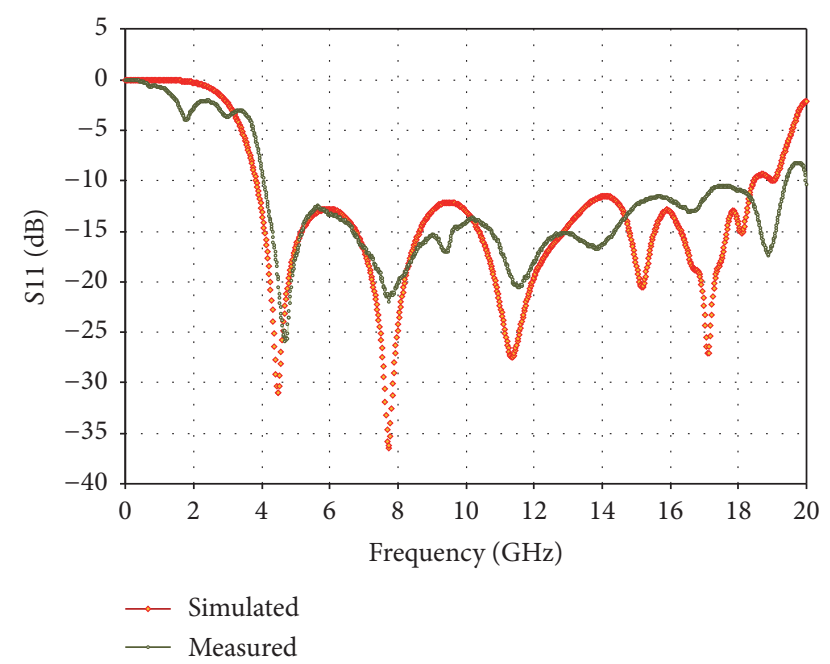

FIgURE 6: Results of measured and simulated values of $S 11$ for the proposed antenna.

Figure 6 demonstrates the widened bandwidth of the proposed antenna, where the measured frequency range is even wider than the simulated one. It has achieved, at the level of $-10 \mathrm{~dB}$, a bandwidth ranging from $4.1 \mathrm{GHz}$ to $19.4 \mathrm{GHz}$, for a total bandwidth of $15.3 \mathrm{GHz}$, while in the conventional antenna the bandwidth was only $0.225 \mathrm{GHz}$.

\section{Dispersion Characteristics}

The possible feasibility of material characterized by simultaneously negative permittivity and permeability was discussed by Veselago [21]. Taking into account the fact that such materials do not exist in the nature, they are called metamaterials. In such materials, the wavevector is antiparallel to the Poynting vector and for this reason they are named "lefthanded materials" or "backward wave media."

In order to check that the designed antenna structure supports backward waves, the dispersion diagram was simulated

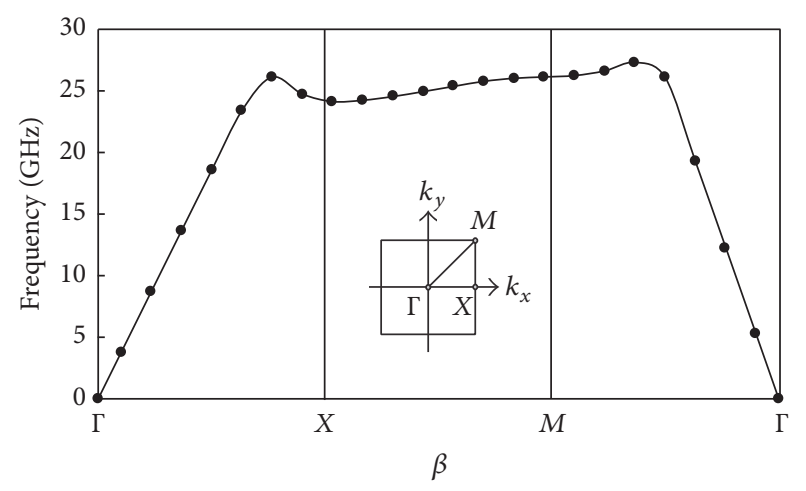

FIgURE 7: The dispersion diagram of the double-fractal based unit cells.

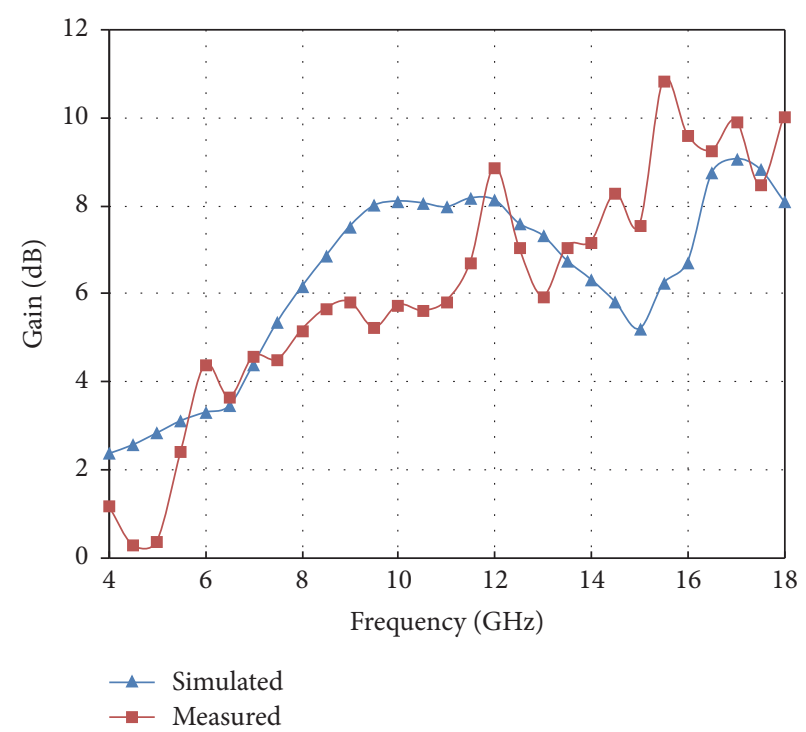

FIGURE 8: The simulated and measured gain of the proposed antenna.

by applying the periodic boundary conditions in the $x$ and $y$ directions of the unit cell. Figure 7 shows the dispersion characteristics of the unit cell along the paths between the high symmetry points $\Gamma, X$, and $M$ of the reduced Brillouin zone, which is plotted in the $\omega$ - $\beta$ curve. In this curve, the slope of the straight line connecting the origin and a certain point on the $\omega-\beta$ curve represents the phase velocity $V_{P}$, and the slope of the line tangential to the curve at that point represents the group velocity $V_{G}$ [21]. It can be noticed from Figure 8 that the slope representing $V_{G}$ is negative, and hence the group velocity and phase velocity are in opposite directions, leading to the conclusion that the structure supports backward waves.

\section{Antenna Gain and Characteristics}

The gain of the proposed antenna was simulated and measured over the working bandwidth, from $4 \mathrm{GHz}$ to $18 \mathrm{GHz}$, as illustrated in Figure 8. The fabricated antenna achieved an average gain of $6 \mathrm{dBi}$ and a maximum value of $10.9 \mathrm{dBi}$. The efficiency improves with the growth of frequency. For 

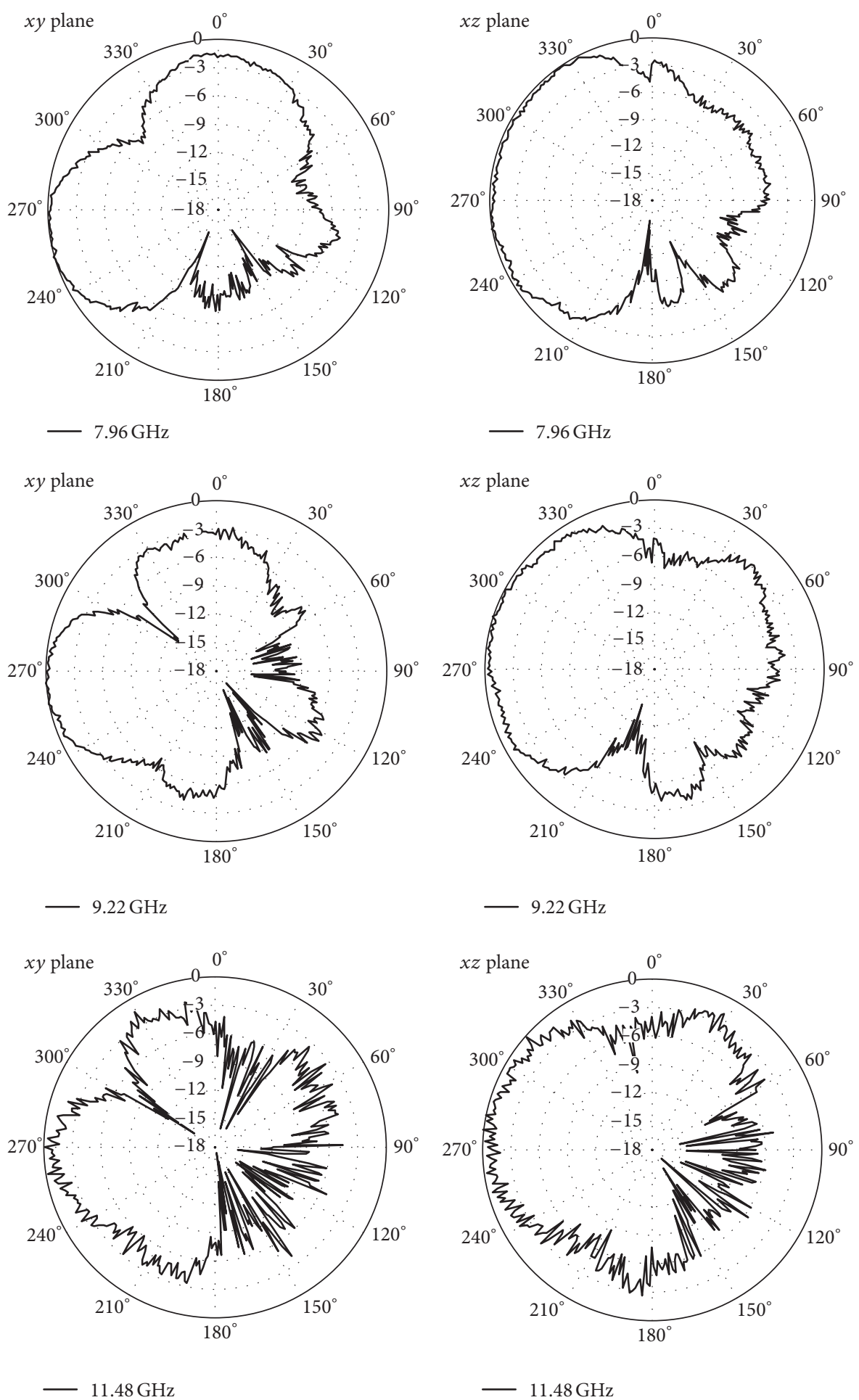

FIGURE 9: The radiation pattern of the proposed antenna at the following frequencies: $7.96 \mathrm{GHz}, 9.22 \mathrm{GHz}$, and $11.48 \mathrm{GHz}$ in the " $x y$ " and “ $x z$ " planes.

frequencies mentioned in Figure 9, the following values of efficiency were obtained: of $86.4 \%$ at $7.96 \mathrm{GHz}$, of $88.3 \%$ at $9.22 \mathrm{GHz}$, and of $89.7 \%$ at $11.48 \mathrm{GHz}$.

The radiation characteristics for the proposed antenna are presented in Figure 9. Radiation patterns were measured in the following frequencies: $7.96 \mathrm{GHz}, 9.22 \mathrm{GHz}$, and
$11.48 \mathrm{GHz}$, in the characteristic planes " $x y$ " and " $x z$." It can be seen that left-handed properties of the antenna resulted in a radiation spread of $270^{\circ}$. It should also be noted that shapes of radiation characteristics change in function of frequency. A similar disadvantage was observed in cases presented in the literature describing microstrip antennas 
with ultrabroadband properties. Future efforts should focus on obtaining similar shapes of radiation patterns in function of frequency to improve the efficiency of radio link.

\section{Conclusion}

In this paper, an ultrawideband antenna based on the planar periodic left-handed metamaterial concept was proposed. The metamaterial property was obtained through the use of a double-fractal structure on both the top and the bottom sides of the antenna. The proposed antenna achieved the frequency range of $4.1 \mathrm{GHz}$ to $19.4 \mathrm{GHz}$, realizing a bandwidth of $15.3 \mathrm{GHz}$. Therefore, the bandwidth of the manufactured antenna is 68 times larger than the bandwidth of the conventional microstrip antenna.

The antenna radiates at a $270^{\circ}$ angle and has an enhanced gain with an average value of almost $6 \mathrm{dBi}$ and a peak of $10.9 \mathrm{dBi}$. The combination of the metamaterial planar concept and the fractal shapes seems to be a good method to enhance the characteristics of the microstrip patch antenna. This antenna can easily be used in a communication system, where such enhanced features are required.

\section{Conflicts of Interest}

The authors declare that they have no conflicts of interest.

\section{Acknowledgments}

This work was carried out with the financial support of the Polish National Centre for Research and Development as Project no. DOB-1-1/1/PS/2014.

\section{References}

[1] G. Kumar and K. C. Gupta, "Broadband microstrip antennas using additional resonators gap-coupled to the radiating edges," IEEE Transactions on Antennas and Propagation, vol. 32, no. 12, pp. 1375-1379, 1984.

[2] U. K. Revankar and A. Kumar, "Experimental investigation of three-layer electromagnetically coupled circular microstrip antennas," Electronics Letters, vol. 27, no. 13, pp. 1187-1189, 1991.

[3] H. F. Pues and A. R. van de Capelle, "Impedance-matching technique for increasing the bandwidth of microstrip antennas," IEEE Transactions on Antennas and Propagation, vol. 37, no. 11, pp. 1345-1354, 1989.

[4] X.-D. Huang, X.-H. Jin, and C.-H. Cheng, "Novel impedance matching scheme for patch antennas," Progress In Electromagnetics Research Letters, vol. 14, pp. 155-163, 2010.

[5] S. Weigand, G. H. Huff, K. H. Pan, and J. T. Bernhard, "Analysis and design of broad-band single-layer rectangular Uslot microstrip patch antennas," IEEE Transactions on Antennas and Propagation, vol. 51, no. 3, pp. 457-468, 2003.

[6] L. Liu, C. Caloz, and T. Itoh, "Dominant mode leaky-wave antenna with backfire-to-endfire scanning capability," Electronics Letters, vol. 38, no. 23, pp. 1414-1416, 2002.

[7] A. Sanada, C. Caloz, and T. Itoh, "Characteristics of the composite right/left-handed transmission lines," IEEE Microwave and Wireless Components Letters, vol. 14, no. 2, pp. 68-70, 2004.
[8] A. I. Anghel and R. Cacoveanu, "Improved composite right/lefthanded cell for leaky-wave antenna," Progress In Electromagnetics Research Letters, vol. 22, pp. 59-69, 2011.

[9] C. Caloz, T. Itoh, and A. Rennings, "CRLH metamaterial leakywave and resonant antennas," IEEE Antennas and Propagation Magazine, vol. 50, no. 5, pp. 25-39, 2008.

[10] M. Palandoken, A. Grede, and H. Henke, "Broadband microstrip antenna with left-handed metamaterials," IEEE Transactions on Antennas and Propagation, vol. 57, no. 2, pp. 331-338, 2009.

[11] C. G. M. Ryan and G. V. Eleftheriades, "A wideband metamaterial meander-line antenna," in Proceeding of the 6th European Conference on Antennas and Propagation (EuCAP '12), pp. 23292331, March 2012.

[12] S. Chaimool, K. L. Chung, and P. Akkaraekthalin, "Bandwidth and gain enhancement of microstrip patch antennas using reflective metasurface," IEICE Transactions on Communications, vol. E93-B, no. 10, pp. 2496-2503, 2010.

[13] N. Matsunaga, A. Sanada, and H. Kubo, "Novel two-dimensional planar negative refractive index structure," IEICE Transactions on Electronics, vol. 89, no. 9, pp. 1276-1282, 2006.

[14] L.-W. Li, Y.-N. Li, T. S. Yeo, J. R. Mosig, and O. J. F. Martin, "A broadband and high-gain metamaterial microstrip antenna," Applied Physics Letters, vol. 96, no. 16, pp. 164101-164103, 2010.

[15] W. J. Krzysztofik, "Fractal geometry in electromagnetics applications from antenna to metamaterials," Microwave Review, vol. 19, no. 2, pp. 3-14, 2013.

[16] J. P. Gianvittorio and Y. Rahmat-Samii, "Fractal antennas: a novel antenna miniaturization technique, and applications," IEEE Antennas and Propagation Magazine, vol. 44, no. 1, pp. 20 36, 2002.

[17] D. H. Werner, R. L. Haupt, and P. L. Werner, "Fractal antenna engineering: the theory and design of fractal antenna arrays," IEEE Antennas and Propagation Magazine, vol. 41, no. 5, pp. 3759, 1999.

[18] D. H. Werner and S. Ganguly, "An overview of fractal antenna engineering research," IEEE Antennas and Propagation Magazine, vol. 45, no. 1, pp. 38-57, 2003.

[19] L. B. Moraes and S. E. Barbin, "A comparison between Minkowski and Koch fractal patch antennas," in Proceeding of the SBMO/IEEE MTT-S International Microwave and Optoelectronics Conference (IMOC '11), pp. 17-21, November 2011.

[20] L. Xiao Zheng, X. Xiang Ming, L. Sheng Li, and X. Zhang, "Analysis of the patch antenna based on the minkowski fractal," in Proceeding of the 4th International Conference on Microwave and Millimeter Wave Technology (ICMMT'04), 2004.

[21] V. Veselago, "The electrodynamics of substances with simultaneously negative values of $\varepsilon$ and $\mu$," Soviet Physics Uspekhi, vol. 10, no. 4, 1968. 


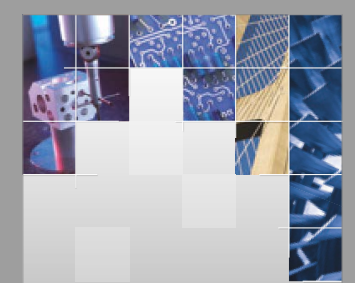

\section{Enfincering}
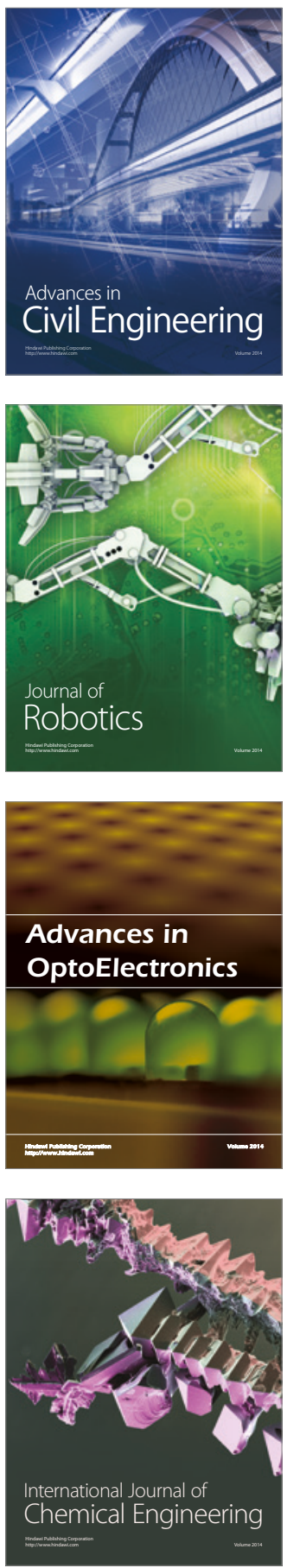

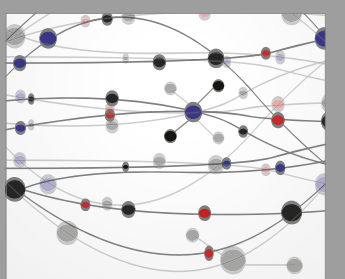

The Scientific World Journal

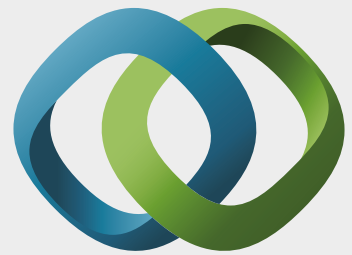

\section{Hindawi}

Submit your manuscripts at

https://www.hindawi.com
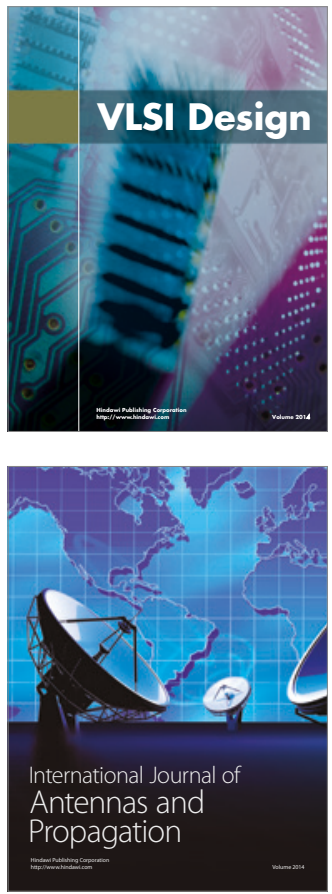

\section{Rotating}

Machinery
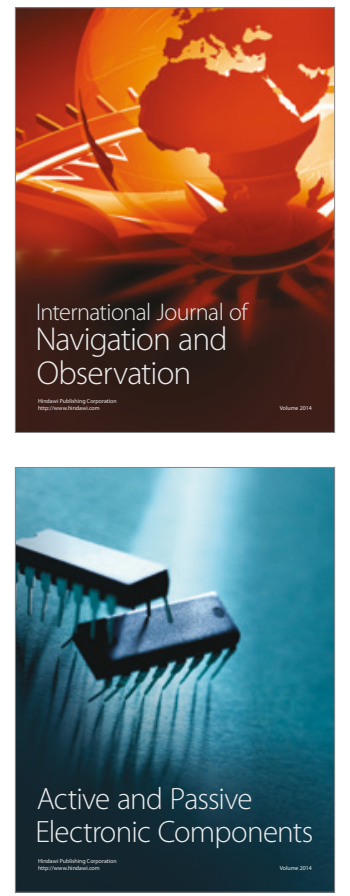
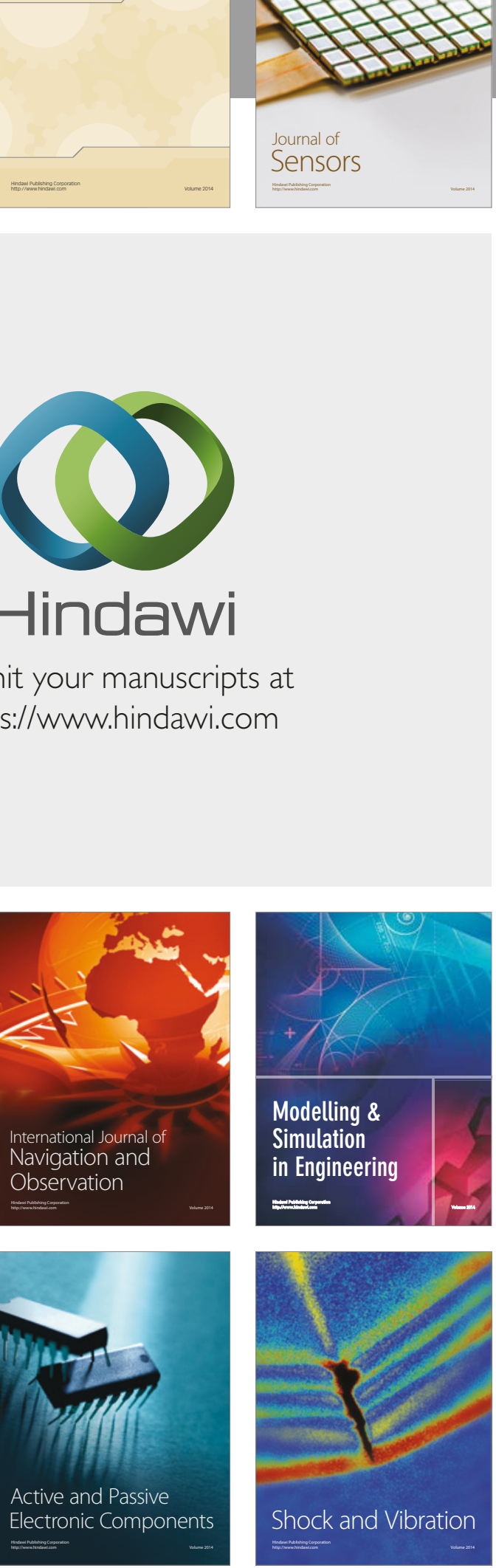
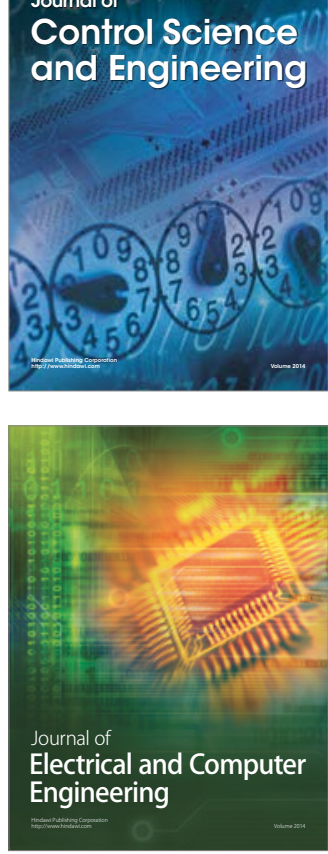

Distributed

Journal of

Control Science

and Engineering
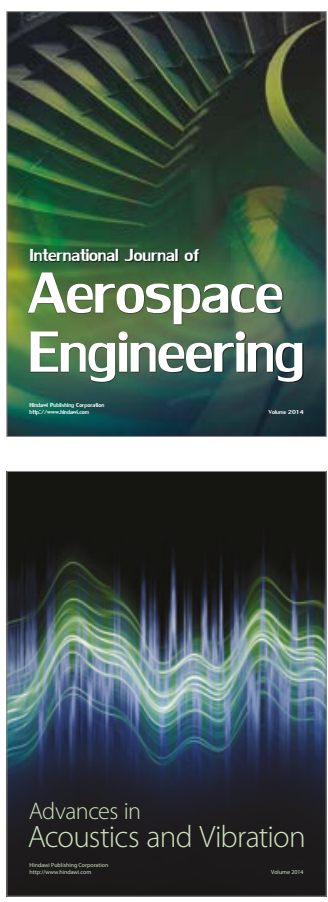

Sensor Networks 